Check for updates

1 Institute of Population Health Sciences, Queen Mary University of London, London, UK

2 HIV/AIDS, Sexually Transmitted Infections, and Tuberculosis

Directorate, Provincial Department of Health, Western Cape Government,

Cape Town, South Africa

Correspondence to: J Freer

j.freer@qmul.ac.uk

Cite this as: BMJ 2022;376:e069807 http://dx.doi.org/10.1136/bmi-2021-069807

Published: 27 January 2022

\section{HIV and covid-19 in South Africa}

\section{The two pandemics must be confronted collectively and globally}

\author{
Joseph Freer, ${ }^{1}$ Vanessa Mudaly ${ }^{2}$
}

Consensus is growing that the omicron variant of SARS-CoV-2, which has 50 mutations differentiating it from the original virus, may have evolved during a prolonged infection in someone with a compromised immune system. ${ }^{12}$ Omicron's likely emergence in southern Africa has raised the question of whether this heavily mutated variant owes its origin to the HIV pandemic, which continues to be a common cause of immunodeficiency in the region.

Around 8 million of South Africa's 60 million population live with HIV, roughly a fifth of all people with HIV globally. ${ }^{3}$ A high proportion of people newly diagnosed in South Africa are at an advanced stage of HIV infection (defined as a CD4 count $<200$ cells $/ \mathrm{mm}^{3}$ ), by which point the immune system is extremely vulnerable. ${ }^{4}$ Many people with advanced HIV in South Africa have started treatment at least once but are not in continuous care or have discontinued treatment. ${ }^{5}$ This underscores the complexity of living with HIV in a resource poor setting, where poverty and stigma are often compounded by unaffordable costs associated with treatment and poor access to mental health services. ${ }^{6}$ Covid-19 has only made these existing challenges harder, having resulted in reduced access to routine care and worrying falls in HIV testing, treatment, and prevention. ${ }^{8} 9$ Together this has left large numbers of immunocompromised people-who are at greater risk of prolonged infections-both more vulnerable to covid-19 and potentially more likely to host mutations of SARS-CoV-2. ${ }^{110} 11$

How should we tackle these synergistic pandemics? The UN's human rights approach has been critical to the effectiveness of responses to HIV and could be constructively applied to covid-19. ${ }^{12}$ This involves improving equitable access to all aspects of healthcare, with service users participating in decision making and providers held accountable for high quality care, while simultaneously addressing the social determinants of health, including discrimination and stigma. These concepts could be applied to covid-19 by channelling public health measures (including vaccination and contact tracing) through existing civil society structures and meaningfully involving citizens - especially marginalised groups such as people with HIV-in the process.

The legacy of South Africa's HIV activism offers a framework on which to model the community engagement that could underpin a human rights based response to covid-19. For two years, the Movement for Change and Social Justice has repurposed strategies developed by HIV activist group the Treatment Action Campaign, which in the 1990 s mobilised South Africans with HIV to campaign for their right to health through litigation, protest, advocacy, and human rights education. ${ }^{1314}$ The Movement for Change and Social Justice has delivered key aspects of local public health responses to covid-19 in South Africa, while also advocating for communities and averting stigma. Further empowerment and integration of such civil society groups could transform access to covid-19 vaccination, diagnostics, and treatments in low and middle income settings.

Delivering sufficient vaccines to supress both transmission and the emergence of variants requires ending "vaccine nationalism," the stockpiling of vaccines for maximal national coverage at the expense of international distribution. ${ }^{15}$ As many people across Europe and North America receive a third vaccine dose, just $7 \%$ of people in Africa have had two. ${ }^{16}$ The global vaccine distribution mechanism Covax delivered fewer than half of the two billion vaccines pledged by the end of 2021, which was already an extremely modest goal. ${ }^{17}$ A prescient modelling study published in Science in August 2021 concluded that "unequal vaccine allocation will result in sustained transmission ... which may result in the emergence of variants with novel antigenicity and/or transmissibility." 18

The "hoard and boost" approach to variants being taken in many high income countries is as futile as it is unethical. The next variant of concern should be pre-empted by increasing vaccination rates in populations with low levels of immunity and high rates of immunocompromise, rather than tackled after its first appearance in a wealthy country.

An urgent refocus on HIV testing and prevention strategies is required to reverse covid-19's devastating effect on access to primary healthcare. People with HIV also need increased support to access treatment, which should include both specific modifications to routine care, such as dispensing for longer periods, and broader approaches to the determinants of health, such as financial and psychological support. ${ }^{19}$

Moving towards an integrated approach to the two diseases will become essential as health systems must preserve or improve HIV care while accommodating the ongoing covid-19 pandemic. Integrated health services also create opportunities to prioritise vaccination of people with HIV and others with compromised immunity. However, to avoid further stigmatisation and discrimination resulting from targeted interventions, this must be community led and delivered within existing public health structures.

As the omicron variant closes in on a world entering its fifth decade of the HIV pandemic, global leaders have the tools to end the health and wealth 
inequalities that are driving both viruses. But while each pandemic continues to fan the flames of the other, neither will end unless both do.

Competing interests: The BMJ has judged that there are no disqualifying financial ties to commercial companies. The authors declare no other interests. Further details of The BM/policy on financial interests are here: https://www.bmj.com/sites/default/files/attachments/resources/2016/03/16-current-bmj-

education-coi-form.pdf.

Provenance and peer review: Not commissioned; externally peer reviewed.

We thank Professor Hassan Mahomed for his comments.

1 Corey L, Beyrer C, Cohen MS, Michael NL, Bedford T, Rolland M. SARS-CoV-2 variants in patients with immunosuppression. N Engl J Med 2021;385:562-6.

doi: 10.1056/NEJMsb2104756. pmid: 34347959

2 Kupferschmidt K. Where did “weird” omicron come from? Science 2021;374:1179. doi: 10.1126/science.acx9738. pmid: 34855502

3 UNAIDS. South Africa. https://www.unaids.org/en/regionscountries/countries/southafrica

4 Carmona S, Bor J, Nattey C, etal. Persistent high burden of advanced HIV disease among patients seeking care in South Africa's national HIV program: data from a nationwide laboratory cohort. Clin Infect Dis 2018;66(suppL_2):S111-7. doi: 10.1093/cid/ciy045. pmid: 29514238

5 Osler M, Hilderbrand K, Goemaere E, etal. The continuing burden of advanced HIV disease over 10 years of increasing antiretroviral therapy coverage in South Africa. Clin Infect Dis 2018;66(suppl_2):S118-25. doi: 10.1093/cid/cix1140. pmid: 29514233

6 Chimbindi N, Bor J, Newell ML, etal. Time and money: the true costs of health care utilization for patients receiving "free" HIV/tuberculosis care and treatment in rural KwaZulu-Natal. / Acquir Immune Defic Syndr2015;70:e52-60. doi: 10.1097/QAl.0000000000000728. pmid: 26371611

7 Ruffieux Y, Efthimiou O, Van den Heuvel LL, etal. The treatment gap for mental disorders in adults enrolled in HIV treatment programmes in South Africa: a cohort study using linked electronic health records. Epidemiol Psychiatr Sci 2021;30:e37.

doi: 10.1017/S2045796021000196. pmid: 33993900

8 Dorward J, Khubone T, Gate K, etal. The impact of the COVID-19 lockdown on HIV care in 65 South African primary care clinics: an interrupted time series analysis. Lancet HIV2021;8:e158-65. doi: 10.1016/S2352-3018(20)30359-3. pmid: 33549166

9 Pillay Y, Pienaar S, Barron P, Zondi T. Impact of COVID-19 on routine primary healthcare services in South Africa. S Afr Med /2021;111:714-9. doi: 10.7196/SAMJ.2021.v111i8.15786

10 Choi B, Choudhary MC, Regan J, etal. Persistence and evolution of SARS-CoV-2 in an immunocompromised host. N Engl / Med 2020;383:2291-3. doi: 10.1056/NEJMc2031364. pmid: 33176080

11 Western Cape Department of Health in collaboration with the National Institute for Communicable Diseases, South Africa. Risk factors for coronavirus disease 2019 (COVID-19) death in a population cohort study from the Western Cape Province, South Africa. Clin Infect Dis 2021;73:e2005-15. doi: 10.1093/cid/ciaa1198. pmid: 32860699

12 United Nations Office of the High Commissioner for Human Rights. HIV/AIDS and the right to health. https://www.ohchr.org/EN/Issues/Health/Pages/HIVandAIDS.aspx

13 Movement for Change and Social Justice. https://www.mymcsj.org/

14 Treatment Action Campaign. https://www.tac.org.za/

15 Hassan F, London L, Gonsalves G. Unequal global vaccine coverage is at the heart of the current covid-19 crisis. BMJ 2021;375:n3074. doi: 10.1136/bmj.n3074. pmid: 34903557

16 African Union Centre for Disease Control and Prevention. Covid-19 vaccination. https://africacdc.org/covid-19-vaccination/

17 United Nations. WHO warns against blanket boosters, as vaccine inequality persists. 2021 Dec 22. https://news.un.org/en/story/2021/12/1108622

18 Wagner CE, Saad-Roy CM, Morris SE, etal. Vaccine nationalism and the dynamics and control of SARS-CoV-2. Science 2021;373:eabj7364. doi: 10.1126/science.abj7364. pmid: 34404735

19 Joint United Nations Programme on HIV/AIDS. Prevailing against pandemics by putting people at the centre-World AIDS Day Report 2020. UNAIDS, 2020.

This article is made freely available for personal use in accordance with BMJ's website terms and conditions for the duration of the covid-19 pandemic or until otherwise determined by BMJ. You may download and print the article for any lawful, non-commercial purpose (including text and data mining) provided that all copyright notices and trade marks are retained. 